\title{
The influence of gastric filling instructions on dose delivery in patients with oesophageal cancer: A prospective study
}

\author{
Citation for published version (APA):
}

Van De Voorde, L., Larue, R., Persoon, L., Oelers, M., Nijsten, S., Bosmans, G., Berbée, M., Swinnen, A., van Elmpt, W., Vanneste, B., Verhaegen, F., \& Lambin, P. (2015). The influence of gastric filling instructions on dose delivery in patients with oesophageal cancer: A prospective study. In Radiotherapy and Oncology Elsevier Ireland Ltd. Radiotherapy and Oncology https://doi.org/10.1016/j.radonc.2015.09.006

Document status and date:

Published: 01/12/2015

DOI:

10.1016/j.radonc.2015.09.006

Document Version:

Publisher's PDF, also known as Version of record

\section{Document license:}

Taverne

\section{Please check the document version of this publication:}

- A submitted manuscript is the version of the article upon submission and before peer-review. There can be important differences between the submitted version and the official published version of record.

People interested in the research are advised to contact the author for the final version of the publication, or visit the DOI to the publisher's website.

- The final author version and the galley proof are versions of the publication after peer review.

- The final published version features the final layout of the paper including the volume, issue and page numbers.

Link to publication

\footnotetext{
General rights rights.

- You may freely distribute the URL identifying the publication in the public portal. please follow below link for the End User Agreement:

www.umlib.nl/taverne-license

Take down policy

If you believe that this document breaches copyright please contact us at:

repository@maastrichtuniversity.nl

providing details and we will investigate your claim.
}

Copyright and moral rights for the publications made accessible in the public portal are retained by the authors and/or other copyright owners and it is a condition of accessing publications that users recognise and abide by the legal requirements associated with these

- Users may download and print one copy of any publication from the public portal for the purpose of private study or research.

- You may not further distribute the material or use it for any profit-making activity or commercial gain

If the publication is distributed under the terms of Article $25 \mathrm{fa}$ of the Dutch Copyright Act, indicated by the "Taverne" license above, 
Adaptive radiotherapy

\title{
The influence of gastric filling instructions on dose delivery in patients with oesophageal cancer: A prospective study
}

\author{
Lien Van De Voorde ${ }^{a, *, 1}$, Ruben Larue ${ }^{\mathrm{a}, 1}$, Lucas Persoon ${ }^{\mathrm{a}}$, Michel Öllers ${ }^{\mathrm{a}}$, Sebastiaan Nijsten ${ }^{\mathrm{a}}$, \\ Geert Bosmans ${ }^{a}$, Maaike Berbée ${ }^{a}$, Ans Swinnen ${ }^{a}$, Wouter van Elmpt ${ }^{a}$, Ben Vanneste ${ }^{a}$, \\ Frank Verhaegen ${ }^{\mathrm{a}, \mathrm{b}}$, Philippe Lambin ${ }^{\mathrm{a}}$ \\ ${ }^{a}$ Department of Radiation Oncology (MAASTRO), GROW School for Oncology and Developmental Biology, Maastricht University Medical Centre+, The Netherlands; and \\ ${ }^{\mathrm{b}}$ Medical Physics Unit, Department of Oncology, McGill University, Montréal, Canada
}

\section{A R T I C L E I N F O}

\section{Article history:}

Received 18 June 2015

Received in revised form 28 August 2015

Accepted 6 September 2015

Available online 10 September 2015

\section{Keywords:}

Oesophageal cancer

Adaptive radiotherapy

Dose-guided radiotherapy

\begin{abstract}
A B S T R A C T
Purpose: To evaluate whether adaptive radiotherapy for unaccounted stomach changes in patients with adenocarcinoma of the gastroesophageal junction (GEJ) is necessary and whether dose differences could be prevented by giving patients food and fluid instructions before treatment simulation and radiotherapy. Material and methods: Twenty patients were randomly assigned into two groups: patients with and without instructions about restricting food and fluid intake prior to radiotherapy simulation and treatment. Redelineation and offline recalculation of dose distributions based on cone-beam computed tomography $(n=100)$ were performed. Dose-volume parameters were analysed for the clinical target volume extending into the stomach.

Results: Four patients who did not receive instructions had a geometric miss $\left(0.7-12 \mathrm{~cm}^{3}\right)$ in only one fraction. With instructions, 3 out of 10 patients had a geometric miss $\left(0.1-1.9 \mathrm{~cm}^{3}\right)$ in one $(n=2)$ or two $(n=1)$ fractions. The $V_{95 \%}$ was reduced by more than $5 \%$ for one patient, but this underdosage was in an in-air region without further clinical importance.

Conclusions: Giving patients food and fluid instructions for the treatment of GEJ cancer offers no clinical benefit. Using a planning target volume margin of $1 \mathrm{~cm}$ implies that there is no need for adaptive radiotherapy for GEJ tumours.
\end{abstract}

(C) 2015 Elsevier Ireland Ltd. All rights reserved. Radiotherapy and Oncology 117 (2015) 442-447
A high level of evidence currently suggests that neoadjuvant chemoradiation (CRT) followed by surgery is the most efficient combination for improving survival in patients with oesophageal cancer [1]. In the Western world, a rise in the incidence of adenocarcinoma is observed, mostly located in the distal oesophagus or at the gastroesophageal junction (GEJ). The oesophagus is drained by a dense plexus of lymphatics, and disease readily spreads microscopically along this plexus, both superiorly and inferiorly from the primary tumour. Because of this behaviour, it is standard treatment planning practice to apply generous margins $(30-50 \mathrm{~mm})$ in the direction of mucosal tumour spread when defining the clinical target volume (CTV) [2]. The importance of this margin was recently shown in a study by Muijs et al. [3] that found that any microscopic remnant outside the radiotherapy field

\footnotetext{
* Corresponding author at: Department of Radiation Oncology, MAASTRO Clinic, Doctor Tanslaan 12, 6929 ET Maastricht, The Netherlands.

E-mail address: Lien.vandevoorde@maastro.nl (L. Van De Voorde).

1 These authors contributed equally to this work.
}

has a high impact on overall survival and disease free survival. For GEJ tumours, the CTV will inevitably extend into the stomach.

Over the course of radiotherapy, the dose delivery will be influenced by a number of factors: e.g. patient setup, anatomical changes and respiratory motion. The latter can be better controlled by implementing four-dimensional computed tomography (4D CT) for treatment simulation. Furthermore, several studies [4-6] have reported that dosimetric errors introduced by respiratory motion tend to average out with fractionation. Unfortunately, even the best gated treatment or breath holding or tracking technique does not take into account interfractional anatomical changes over the course of a treatment. It is recognised that heterogeneous variations in stomach shape and volume occur which may complicate target localisation and reproducibility during simulation and treatment [7-9]. Intake of food or carbonated drinks can cause gastric distension with a consequent shift of the CTV extending along the mucosal wall of the stomach. This shift could potentially influence dose coverage. In the ideal setting stomach shape and volume are conserved during radiotherapy, which could be assured by restricting food and carbonated drinks three hours before treat- 
ment. On the other hand, patients with oesophageal cancer often have problems maintaining their calorie intake and it is not preferable to change their dietary habits. With the implementation of image-guided radiotherapy (IGRT) and dose recalculation based on the kilovoltage cone-beam computed tomography ( $\mathrm{kV} \mathrm{CBCT}$ ), we can calculate the delivered dose to the target volume during treatment and eventually adjust treatment if necessary $[10,11]$.

This study has two main objectives: (1) to investigate the necessity of adaptive radiotherapy for patients with GEJ tumours in case of unaccounted stomach changes e.g. gas pockets in the stomach; (2) to evaluate the impact of food and fluid instructions to assess verification of geographic miss due to variation in gastric volume. A quantitative analysis is performed by comparing the dose distributions recalculated on cone-beam CT images (dose-of-the-day) of the patients' anatomy during the radiotherapy sessions compared to the planned dose.

\section{Materials and methods}

\section{Patients}

This prospectively designed study had the approval of our Internal Review Board; our clinical protocol was registered at https://clinicaltrials.gov/ct2/show/NCT02130011. Twenty patients with pathologically confirmed GEJ tumours were included. They were treated with (neoadjuvant) CRT between May 2013 and July 2014. All patients had tumour stage cT2-3N1-3. No patient needed gastrostomy or nasal tube feeding before starting treatment.

We randomly assigned patients to two groups:

(1) Ten patients received food and fluid instructions before treatment simulation and radiotherapy treatment. They were asked to fast (ingest no food or carbonated drinks) for at least three hours before treatment simulation and radiotherapy planning.

(2) Ten patients received no instructions for gastric emptying or filling.

\section{CT scanning}

Patients were scanned in a supine position and immobilised using an adjustable cranial and upper arm support (Civco, Posirest-2, USA) and a kneefix cushion device (Civco, Posirest-2, USA). All patients underwent a respiratory-correlated 4D CT scan (Sensation Open, Siemens Erlangen, Germany) using $140 \mathrm{kV}$ and $800 \mathrm{mAs}$ with $3 \mathrm{~mm}$ reconstructed slice thickness to incorporate intrafractional mobility of the target volume. The CT number to electron density calibration of the 4D-CT scan was undertaken using a Gammex CT phantom with tissue-equivalent inserts (Gammex Inc., Wisconsin, USA).

\section{Target volume delineation}

The gross tumour volume (GTV) was delineated by experienced radiation oncologists on the mid-expiration phase of the 4D CT scan, using all available diagnostic information. An expansion of the GTV by $3 \mathrm{~cm}$ is used in the superior and inferior direction to define the thoracic (CTV_thor) and abdominal (CTV_abd) part of the CTV, respectively. We applied a $1 \mathrm{~cm}$ margin in the radial dimension, excluding normal tissue. In terms of radiotherapy fields, our institution irradiated prophylactic nodal areas according to the primary tumour site [12]. For this study, only the CTV_abd was of particular interest, compatible with extension of the target volume along the gastric wall. The abdominal planning target volume (PTV_abd) was generated by expanding the CTV_abd with a $1 \mathrm{~cm}$ margin to account for setup uncertainties. For the thoracic part of the tumour we applied a $5 \mathrm{~mm}$ PTV margin (PTV_thor). In this way we limit the volume of lung irradiation and consequently treatment-related complications.

\section{Treatment planning and verification}

Radiotherapy consisted of administering a radiation dose of $41.4 \mathrm{~Gy}$ or $50.4 \mathrm{~Gy}$ in 23 or 28 daily fractions of $1.8 \mathrm{~Gy}$, five times per week. We used the Eclipse treatment planning system (Varian Medical Systems, Palo Alto, USA) to generate a RapidArc plan that ensured PTV coverage by the 95\% isodose in accordance with the International Commission on Radiation Units and Measurements report 83 and fulfilled the planning constraints for the critical organs $[13,14]$. One patient (Appendix A: patient $n^{\circ} 3$ ) had a seven-field intensity-modulated radiotherapy plan for which the Anisotropic Analytical Algorithm (AAA version 10.0.28) in Eclipse was used to calculate dose. For the other patients, dose was calculated by the Acuros XB algorithm in Eclipse version 10.0.28 (Varian Medical Systems, Palo Alto, USA).

All beam deliveries had pretreatment verification with an electronic portal imaging device which is an important part of our inhouse patient-specific quality assurance programme for these advanced treatment techniques [15].

\section{Workflow of dose-guided radiotherapy}

To determine the estimated delivered dose and investigate the influence of potential gastric and consequent CTV_abd variation during radiation treatment, we developed the following procedure (Fig. 1).

Step 1: After positioning the patient on the couch for treatment, we acquired a kV CBCT image $(125 \mathrm{kV}, 262 \mathrm{mAs}, 13 \mathrm{~s}$ acquisition time) to align the patient as closely as possible to the planned position using a match of bony structures. After the automatic image rigid registration based on mutual information, the radiation therapists could perform an additional manual rigid image registration to ensure proper alignment of soft tissue in the CTV_abd region. We performed IGRT on a daily basis throughout the treatment course for on-line setup correction and for visual detection of anatomical changes.

Step 2: The GTV was copied to the $\mathrm{kV} \mathrm{CBCT}$ of fractions $1,6,11$, 16 and 21 for all patients and after visual inspection there was no need to adjust the GTV delineation. Furthermore, redelineation of the CTV_abd was performed on the $\mathrm{kV} \mathrm{CBCT}$ and a second radiation oncologist reviewed delineation on these $100 \mathrm{kV}$ CBCTs. The PTV_abd of the initial planning CT was copied without alteration to the respective $\mathrm{kV} \mathrm{CBCT}$. No other structures were redelineated because they were of no further relevance for this study. Geographic miss was defined as expansion of the redelineated CTV_abd outside the initial planned PTV_abd. This was checked by visual inspection and calculated as the volume of the CTV_abd subtracted from the existing planned PTV_abd.

Step 3: Due to the limited field of view (FOV) of the $\mathrm{kV} \mathrm{CBCT}$ acquisition, total PTV length systematically oversised the kV CBCT. We developed a validated automated method for accurately stitching the three-dimensional CT data to the $\mathrm{kV} \mathrm{CBCT}$ data, using an image registration scheme (Appendix B). Preliminary experimental results demonstrated that "3D data stitching" provides a good solution to the voxel mismatch caused by limited FOV length in the craniocaudal direction [16]. For the treatment of oesophageal cancer, radiotherapy fields are often large and stitching is a suitable solution for features like CTV_abd near a field boundary especially when part of the beam is out of the field geometry.

Step 4: We performed a registration of the stitched $\mathrm{kV}$ CBCT to the initial planning $\mathrm{CT}$ and recalculated the 3D dose distribution to the patient on the $\mathrm{kV}$ CBCT. To achieve higher accuracy in $\mathrm{kV}$ CBCT image-based dose calculation, we used a calibration method 


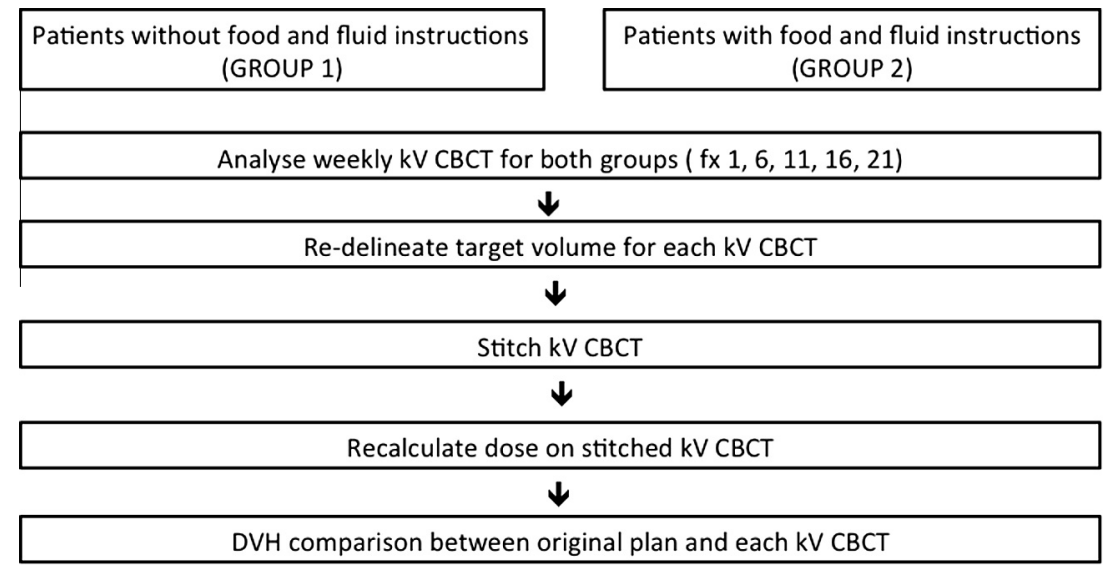

Fig. 1. Workflow 'how to recalculate dose on $\mathrm{kV}$ CBCT'.

with the Computerized Imaging Reference Systems (CIRS) water equivalent electron density phantom (model 062, Norfolk, Virginia). Although high density inhomogeneities still are challenging for the reconstruction process, there is evidence that clinically acceptable agreement in key dose-volume parameters between CT-based and kV CBCT-based planning calculation exists [17]. The same calculation algorithm and preset MU values of the beams in the initial treatment planning were used.

Step 5: In the final step, we compared the reconstructed dosevolume histogram $(\mathrm{rDVH})$ parameters from the $\mathrm{kV} \mathrm{CBCT}$ with the DVH parameters from the initial planning CT. Potential dosimetric changes to the CTV_abd are the quantities of interest for comparing plans in which patients were and were not given food and fluid instructions. We focused on the following DVH parameters: volume receiving $\geqslant 95 \%, \geqslant 99 \%$ and $\geqslant 107 \%$ of the prescribed dose $\left(V_{95 \%}, V_{99 \%}\right.$ and $V_{107 \%}$ ). In addition, we analysed the dose to $5 \%$ of the volume ( $D_{5 \%}$ or near-maximum dose) and the mean, minimum and maximum dose $\left(D_{\text {mean }}, D_{\min }\right.$ and $\left.D_{\text {max }}\right)$ for CTV_abd. In this study, the altered dose distribution was considered a significant change if [18]:

- $V_{95 \%}$ of $C T V \_a b d$ decreased by more than $5 \%$ compared to the initial planning $\mathrm{CT}$

- $D_{\text {mean }}$ of CTV_abd decreased by more than $5 \%$ compared to the initial planning $\mathrm{CT}$

- The percentage of $D_{5 \%}$ increased by more than $5 \%$ compared to the initial planning $\mathrm{CT}$

\section{Results}

The pre-treatment verification revealed no significant dose differences for any of the patients, indicating that irradiation was performed as planned. Fig. 2 shows the results of the $\mathrm{kV} \mathrm{CBCT}$ dose recalculation for the patient cohort (see Appendix A for more detailed DVH parameters).

Of the ten patients who did not receive food and fluid instructions, we detected a geographic miss in four patients (Appendix A: patient $n^{\circ} 1,3,4$ and 5 ). This notable variation in stomach and CTV_abd movement and shape was limited to one CBCT per patient. Coverage of CTV_abd was still excellent in these fractions with no reduction of more than $5 \%$ compared to the initial planning CT (Fig. 3).

Of the ten patients who received instructions to fast three hours before simulation and radiotherapy, we observed a geographic miss in three patients (Appendix A: patient $n^{\circ} 17,18$ and 20). For two patients geographic miss was on one $\mathrm{CBCT}$ and for one patient on two CBCTs. In this latter patient, $\mathrm{kV}$ CBCT of fraction 6 and 11

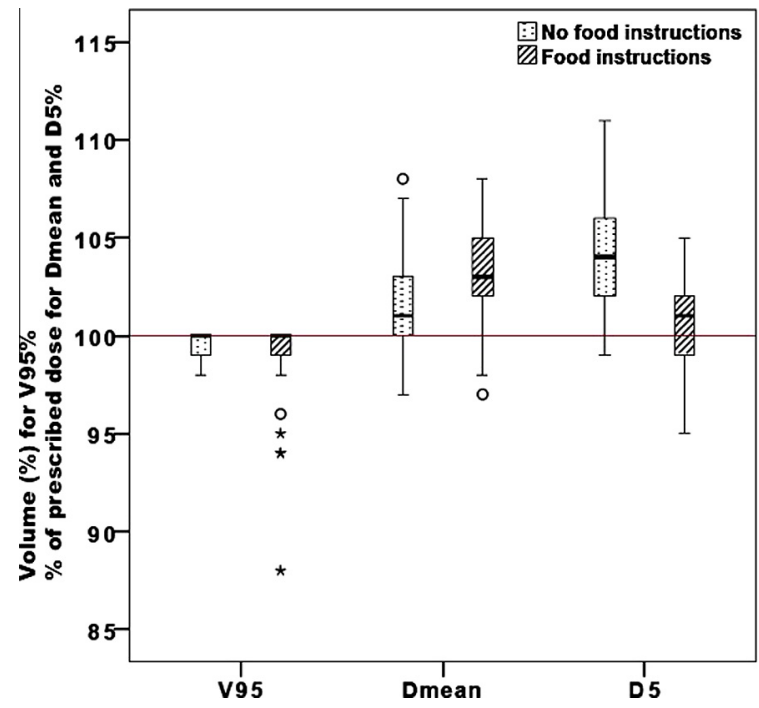

Fig. 2. Box-and-Whisker plot shows the distribution of the initial and recalculated dose in our two cohorts. Dark horizontal lines represent the median, with the box representing the 25th and 75th percentiles, the whiskers the 5th and 95th percentiles. Outliers are marked with circles: $1.5 *$ interquartile range (IQR) $<x<3{ }^{*}$ IQR from the box. Asteriks represent extreme outliers defined by $x>3 *$ IQR from the box.

revealed a gastric gas pocket localised in the CTV_abd. This gas pocket was not present on the initial planning CT (Fig 4). This is the only patient in whom we observed more than $5 \%$ reduction in dose coverage but this was not in the region of the CTV_abd part that was outside the PTV_abd. Looking in more detail, we realised that the underdosage was situated in an in-air- PTV_abd region caused by the gas pocket. This observation did not lead to adaptive treatment planning in this patient.

Comparing the CBCT plan to the treatment plan there was no significant difference between the two groups for $V_{95 \%}, D_{\text {mean }}$ and $D_{5 \%}$. In one fraction (Appendix A: patient $n^{\circ} 5$ ) we observed an increase of $D_{5 \%}$ with $6 \%$ but this was not considered alarming. For both treatment groups, there was no decline of $D_{\text {mean }}$ of more than $5 \%$ and no increase of $D_{5 \%}$ with more than $5 \%$. In general, we observed a trend towards a higher $D_{\max }$ and $V_{107 \%}$ in all CBCTs (Appendix A: patients $\mathrm{n}^{\circ} 3$ and 15 ) or a limited number of CBCTs (Appendix A: patient $n^{\circ} 2$ and 20) compared to the planning CT. When we looked at the $D_{5 \%}$ instead of the $V_{107 \%}$ the dose-volume differences were considerably smaller. After matching the PTV_abd on the slow $\mathrm{kV}-\mathrm{CBCT}$ to the initial planning mid-expiration $\mathrm{CT}$, we 


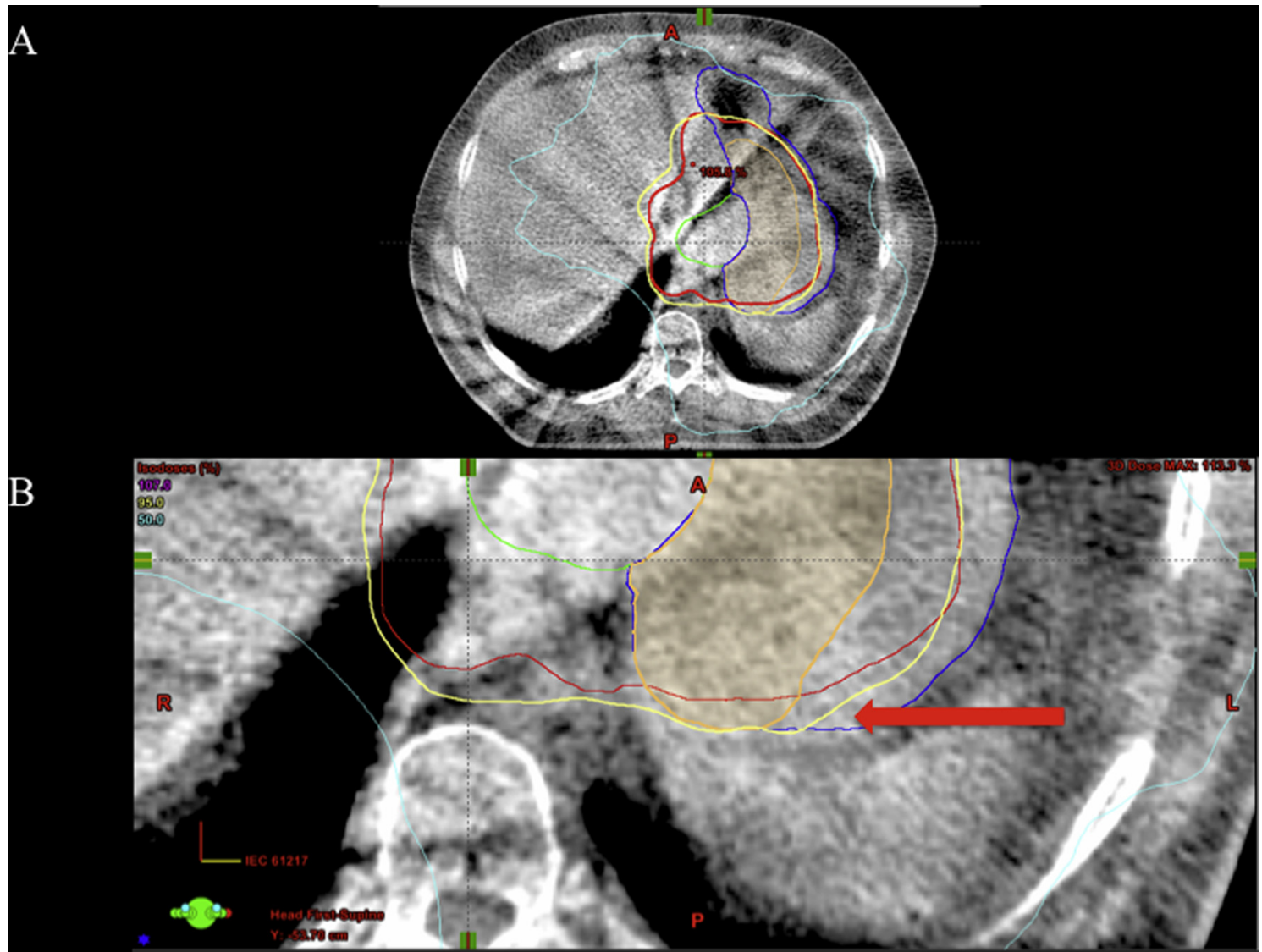

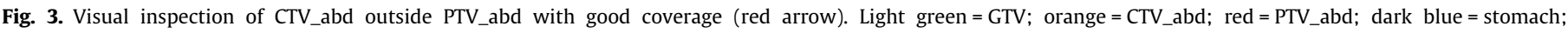

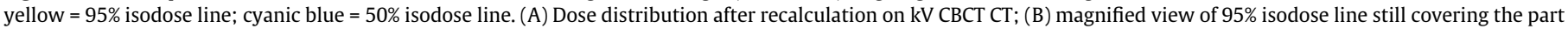
of CTV_abd located outside the PTV_abd. (For interpretation of the references to colour in this figure legend, the reader is referred to the web version of this article.)

observed in these patients that the beam was less attenuated by absorption as it passed through more air. Details about the image characteristics are given in Appendix C. Using highly conformal irradiation techniques, a steep dose fall-off in treatment planning for oesophageal cancer was created; so the smallest shift of the dose distribution (e.g. because of an aberrant breathing pattern) may result in a large shift of dose-volume metrics. Although this was not the scope of our study, these additional findings show the dependency on respiratory motion in CBCT dose recalculation. This could be solved by using the first day of CBCT data sets rather than planning CT to provide reliable dosimetric parameters comparison. As a result of evaluating the dose-volume histogram data listed in Fig. 2, there seemed to be no need for adaptive radiotherapy planning based on both quantitative dose analysis and visual interpretation of the $\mathrm{kV} \mathrm{CBCT}$.

\section{Discussion}

Nowadays, IGRT is widely used for correctly positioning patients, but in this study we focused on the kV CBCT imaged gastric anatomic changes of patients with GEJ tumours. We investigated CBCT for dose calculation to predict and assess the dose delivered to the patient and use it for adaptive radiotherapy. We monitored a total $100 \mathrm{kV}$ CBCTs from 20 patients who either were or were not instructed to restricted intake of food or carbonated drinks three hours before simulation and treatment. Only one patient did not achieve the pre-determined rDVH criteria with reduced dose coverage. However, this reduced dose coverage was in air and was not clinically relevant to the treatment protocol.
Although this was only a weekly dose recalculation instead of a daily analysis, we expect no large shift of the integral and cumulative dose distribution relative to the CTV abd since we found no systematic errors. Even with a strict gastric filling scenario, physiological organ motion and shape variation seems unpredictable and unavoidable. Our study affirms that giving no instructions is the correct approach for patients with GEJ tumours who already often have difficulties maintaining their dietary habits during CRT. Still when thinking of reducing PTV margin to less than $1 \mathrm{~cm}$, paying attention to image-guided based patient setup error and instructing radiation therapists to observe potential geometric misses are strategies that can be utilised to reduce compromised coverage of the CTV. Future research should extend this study with more participants to further confirm these results.

A study by Bouchard et al. [19] also focused on GEJ tumours and found that the filling status of the stomach had no impact on the actual dose to the GTV. However when there is an increase in gastric volume, they warn against neglecting the inadequate doses to the PTV, which could result in small geographic misses. Bouchard et al. [19] did not analyse the potential dosimetric errors induced by gas pockets or different filling state of the stomach during radiotherapy treatment.

The advantage of our study is that it brings the focus back to the main objective of radiotherapy: namely ensuring that the prescribed dose is delivered to the correct location. Organs like the stomach may inflate and deflate over time and we focused on the part of the target volume which is most prone to variability: the part of the CTV extending into the stomach. Since a dose deficit to a $1 \%$ volume of the target that is larger than $20 \%$ of the prescription dose still may lead to serious loss of tumour control probabil- 


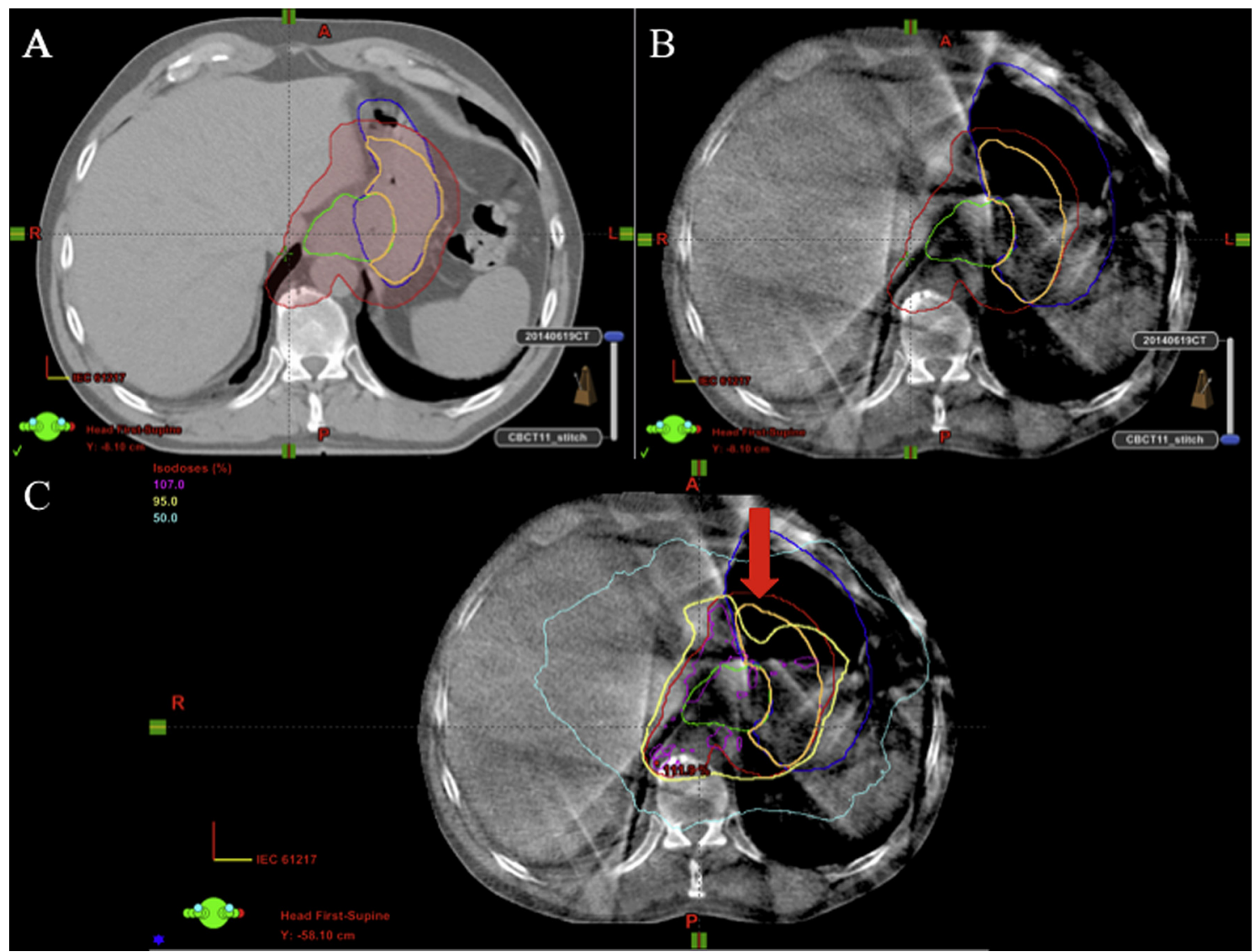

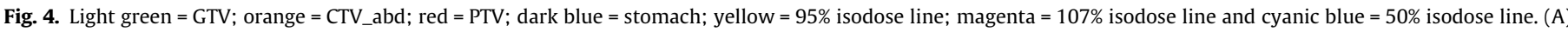

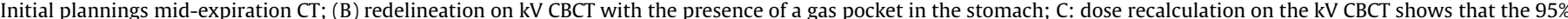

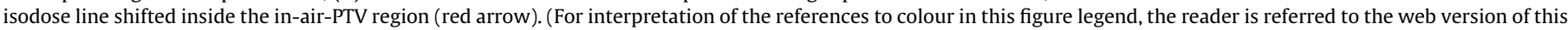
article.)

ity, it is important to pay attention to small-volume cold regions in the target [20]. In our study the biological impact of small CTV_abd expansion outside the PTV_abd was considered to be limited. Modest cold spots as observed in our study will likely not reduce tumour control probability unduly $[21,22]$. Our study information may also prove useful if any questions arise about patient guidelines for food and fluid during treatment for GEJ cancer.

The major drawback of our study is the offline approach, including the fact that the radiotherapy fraction had already been delivered before a possible insufficient dose coverage was detected. We did not investigate the influence of dose-volume parameter differences in organs at risk. We do not expect a violation of dose constraints to the gastric fundus regarding the potential influence of postoperative anatomic leakage [23]. We recognise that patients' dietary compliance was only tracked on a weekly basis. Another limitation is the limited reconstruction length of the $\mathrm{kV} \mathrm{CBCT}$ (i.e. $17 \mathrm{~cm}$ ) where the PTV length systematically exceeded these features. Further developments in merging sectional CBCTs into an accurate, larger single image would overcome the limitation of the small FOV of CBCT [24]. The mid-expiration phase of treatment planning is only a snapshot in time, while $\mathrm{kV} \mathrm{CBCT}$ acts as a slow CT in which breathing and peristaltic motion create rather blurry images. The current study has shown that the relative motion and position of the tumour at the time of treatment may not match that of the planning 4DCT scan. Patients can present with different respiratory patterns during radiotherapy treatment [25]. Respiratory-correlated cone beam could improve imaging quality and correct recalculation. Visual qualitative inspection of CBCT scans and redelineation of target volumes is time- consuming and prone to inter-observer variation in human interpretation. The image quality was clinically sufficient to delineate the stomach, but the uncertainty for the manual delineation of other structures and OARs is high due to the poor image quality and artifacts caused by gas-pockets and therefore merely enough for the purpose of adaptive radiotherapy [26]. The kV CBCT image quality continues to improve: recent results indicate a $1-2 \%$ softtissue contrast resolution $[27,28]$. Dose recalculation on $\mathrm{kV} \mathrm{CBCT}$ should be done with clear awareness of its limitations and a reliable calibration between the pixel values (reconstructed greyscale values) within the reconstructed image and the electron density of the material being imaged is mandatory, especially in the presence of air gaps and metal artifacts [29]. These inconsistencies and artifacts are inherent to the use of $\mathrm{kV} \mathrm{CBCT}$, which might be solved by technological advances.

Ideally, we would perform on-line adaptive radiotherapy in order to monitor and modify dose before treatment delivery 'online'. Until now, the many steps involved before one can display the estimated delivered dose distribution on a near real-time image like $\mathrm{kV} \mathrm{CBCT}$, have made it difficult to implement this in daily clinical practice. There are application tools to automate some of these steps (e.g. auto-propagation of contours) and facilitate the workflow process, but these are not yet sufficiently well integrated into current commercial platforms to use on a daily scale.

In addition to a better matching of the patient's position, IGRT with $\mathrm{kV}$ CBCT images offers a more powerful use to reconstruct the estimated delivered dose. To our knowledge, this is the first study to investigate variations in gastric dimension and their effect 
on the (near) real-time given dose. Our study summarises the work needed to implement dose-guided radiotherapy with $\mathrm{kV}$ CBCT for patients with GEJ tumours and comments on the remaining challenges. We conclude that when an adequate PTV margin of $1 \mathrm{~cm}$ is applied, dietary instructions do not contribute to optimal target coverage. CBCT before treatment does provide information on interfractional and interindividual variations in stomach volume for GEJ tumours but there is currently no need for adaptive treatment planning.

\section{Conflict of interest}

None.

\section{Acknowledgments}

Authors acknowledge financial support from the QuIC-ConCePT project, which is partly funded by EFPI A companies and the Innovative Medicine Initiative Joint Undertaking (IMI JU) under Grant Agreement No. 115151. This research is also supported by the Dutch technology Foundation STW (Grant No. 10696 DuCAT), which is the applied science division of NWO, and the Technology Programme of the Ministry of Economic Affairs. Authors also acknowledge financial support from EU 7th framework program (ARTFORCE, REQUITE).

\section{Appendix A. Supplementary data}

Supplementary data associated with this article can be found, in the online version, at http://dx.doi.org/10.1016/j.radonc.2015.09. 006.

\section{References}

[1] van Hagen P, Hulshof MC, van Lanschot JJ, et al. Preoperative chemoradiotherapy for esophageal or junctional cancer. N Engl J Med 2012:366:2074-84.

[2] Gao XS, Qiao X, Wu F, et al. Pathological analysis of clinical target volume margin for radiotherapy in patients with esophageal and gastroesophageal junction carcinoma. Int J Radiat Oncol Biol Phys 2007;67:389-96.

[3] Muijs C, Smit J, Karrenbeld A, et al. Residual tumor after neoadjuvant chemoradiation outside the radiation therapy target volume: a new prognostic factor for survival in esophageal cancer. Int J Radiat Oncol Biol Phys 2014;88:845-52.

[4] Bortfeld T, Jiang SB, Rietzel E. Effects of motion on the total dose distribution. Semin Radiat Oncol 2004;14:41-51.

[5] Chui CS, Yorke E, Hong L. The effects of intra-fraction organ motion on the delivery of intensity-modulated field with a multileaf collimator. Med Phys 2003;30:1736-46.

[6] George R, Keall PJ, Kini VR, et al. Quantifying the effect of intrafraction motion during breast IMRT planning and dose delivery. Med Phys 2003:30:552-62.

[7] van der Geld YG, Senan S, van Sornsen de Koste JR, et al. A four-dimensional CT-based evaluation of techniques for gastric irradiation. Int J Radiat Oncol Biol Phys 2007:69:903-9.
[8] Yaremko BP, Guerrero TM, McAleer MF, et al. Determination of respiratory motion for distal esophagus cancer using four-dimensional computed tomography. Int J Radiat Oncol Biol Phys 2008;70:145-53.

[9] Watanabe $\mathrm{M}$, Isobe $\mathrm{K}$, Takisima $\mathrm{H}$, et al. Intrafractional gastric motion and interfractional stomach deformity during radiation therapy. Radiother Oncol 2008;87:425-31.

[10] Chen J, Morin O, Aubin M, et al. Dose-guided radiation therapy with megavoltage cone-beam CT. Br J Radiol 2006;79:S87-98 [Spec No 1].

[11] Persoon LC, Egelmeer AG, Ollers MC, et al. First clinical results of adaptive radiotherapy based on $3 \mathrm{D}$ portal dosimetry for lung cancer patients with atelectasis treated with volumetric-modulated arc therapy (VMAT). Acta Oncol 2013:52:1484-9.

[12] Van De Voorde L, Larue RT, Pijls M, et al. A qualitative synthesis of the evidence behind elective lymph node irradiation in oesophageal cancer. Radiother Oncol 2014;113:166-74.

[13] Chavaudra J, Bridier A [Definition of volumes in external radiotherapy: ICRU reports 50 and 62]. Cancer Radiother 2001;5:472-8.

[14] Gregoire V, Mackie TR. State of the art on dose prescription, reporting and recording in intensity-modulated radiation therapy (ICRU report No. 83). Cancer Radiother 2011;15:555-9.

[15] van Elmpt W, McDermott L, Nijsten S, et al. A literature review of electronic portal imaging for radiotherapy dosimetry. Radiother Oncol 2008;88: 289-309.

[16] Petit SF, van Elmpt WJ, Lambin P, Dekker AL. Dose recalculation in megavoltage cone-beam CT for treatment evaluation: removal of cupping and truncation artefacts in scans of the thorax and abdomen. Radiother Oncol 2010;94:359-66.

[17] Elstrom UV, Olsen SR, Muren LP, et al. The impact of CBCT reconstruction and calibration for radiotherapy planning in the head and neck region - a phantom study. Acta Oncol 2014;53:1114-24.

[18] Moller DS, Khalil AA, Knap MM, Hoffmann L. Adaptive radiotherapy of lung cancer patients with pleural effusion or atelectasis. Radiother Oncol 2014;110:517-22.

[19] Bouchard M, McAleer MF, Starkschall G. Impact of gastric filling on radiation dose delivered to gastroesophageal junction tumors. Int J Radiat Oncol Biol Phys 2010;77:292-300.

[20] Tome WA, Fowler JF. On cold spots in tumor sub volumes. Med Phys 2002;29:1590-8

[21] Goitein M, Niemierko A. Intensity modulated therapy and inhomogeneous dose to the tumor: a note of caution. Int J Radiat Oncol Biol Phys 1996;36:519-22.

[22] Niemierko A, Goitein M. Implementation of a model for estimating tumor control probability for an inhomogeneously irradiated tumor. Radiother Oncol 1993:29:140-7.

[23] VandeWalle C, Ceelen WP, Boterberg T, et al. Anastomotic complications after Ivor Lewis esophagectomy in patients treated with neoadjuvant chemoradiation are related to radiation dose to the gastric fundus. Int J Radiat Oncol Biol Phys 2012;82:e513-9.

[24] Kim MK, Kang SH, Lee EH, et al. Accuracy and validity of stitching sectional cone beam computed tomographic images. J Craniofac Surg 2012;23: 1071-6.

[25] Purdie TG, Moseley DJ, Bissonnette JP, et al. Respiration correlated cone-beam computed tomography and 4DCT for evaluating target motion in Stereotactic Lung Radiation Therapy. Acta Oncol 2006;45:915-22.

[26] Njeh CF, Dong L, Orton CG. Point/counterpoint. IGRT has limited clinical value due to lack of accurate tumor delineation. Med Phys 2013;40:040601.

[27] Jaffray DA, Siewerdsen JH. Cone-beam computed tomography with a flat-panel imager: initial performance characterization. Med Phys 2000;27:1311-23.

[28] Seppi EJ, Munro P, Johnsen SW, et al. Megavoltage cone-beam computed tomography using a high-efficiency image receptor. Int J Radiat Oncol Biol Phys 2003;55:793-803.

[29] Rong Y, Smilowitz J, Tewatia D, et al. Dose calculation on kV cone beam CT images: an investigation of the Hu-density conversion stability and dose accuracy using the site-specific calibration. Med Dosim 2010;35:195-207. 